\title{
Estimating the Cost of a New Technology Intensive Automotive Product: A Case Study Approach
}

\author{
Rajkumar Roy ${ }^{\mathrm{i}}$, Scott Colmer ${ }^{\mathrm{ii}}$ and Terry Griggsiii \\ ' Department of Enterprise Integration, SIMS, Cranfield University, Cranfield, Bedford, MK43 0AL, United \\ Kingdom. +44 (0)1234 754073, r.roy@cranfield.ac.uk \\ ii Ford Motor Co., Room 1B-F07, Dunton Tech. Centre, Basildon, Essex SS15 6EE United Kingdom. +44 \\ (0)1268 403441, scolmer@ford.com \\ iii Ford Motor Co., Room 762 Trafford House, 8 Station Way, Basildon, Essex SS16 5XX United \\ Kingdom. +44(0)1268 703418, tgriggs@ford.com
}

\begin{abstract}
Estimating cost of new technology intensive products is very ad hoc within the automotive industry. There is a need to develop a systematic approach to the cost estimating, which will make the estimates more realistic. This research proposes a methodology that uses parametric, analogy and detailed estimating techniques to enable a cost to be built for an automotive powertrain product with a high content of new technology. The research defines a process for segregating new or emerging technologies from current technologies to enable the various costing techniques to be utilised. The cost drivers from an internal combustion engine's characteristics to facilitate a cost estimate for high volume production are also presented. A process to enable a costing expert to either build an estimate for the new technology under analysis or use a comparator and then develop a variant for the new system is also discussed. Due to the open nature of the statement 'new technology', research is also conducted to provide a meaningful definition applicable to the automotive industry and this project.
\end{abstract}

Keywords: Cost Estimating, Cost Engineering, Cost of New Technology, Cost Prediction, Automotive Product Cost 


\section{Estimating the Cost of a New Technology Intensive Automotive Product: A Case Study Approach}

\section{Introduction}

The automotive, aerospace and defence industries often have to estimate the cost of a product that contains significant amounts of new technology, and so requires considerable experience of previous projects, technology trends and new developments in other industry sectors. This paper presents a case study approach for the development of a cost model methodology that can be used to estimate the costs of a new technology-intensive product. The cost drivers involved in estimating the cost of these products are identified together with the need for expert judgement in the estimating process.

The paper is structured in eleven sections. The next section identifies relevant research in cost estimating and presents current practices within automotive and non-automotive sectors, especially focusing on new technology cost estimating processes. It is important to understand the nature of new technology therefore section 3 defines new technology and relates the definition to the automotive sector. The following section presents an overview of the methodology developed for the cost estimating. The methodology has three major steps: identification of new and 'carry-over' technologies, cost estimating both the parts and finally adjusting cost models due to the difference in sources of data used. The methodology is developed using a case study approach on powertrain cost estimating. Once the 'carry-over' technology intensive parts are identified, the cost is estimated based on historical data (section 5). Estimating the cost of the parts that are new technology based is trickier; it requires a comparative study with previous knowledge within other sectors (section 6). The model developed as a result of the case study is fine adjusted to reflect the difference in time frame of the source data in section 7 . The methodology is then validated using two case 
studies, discussed in section 8 and 9. Discussion on the research methodology and results obtained are presented in section 10, and finally the paper concludes in section 11 and proposes future improvements to the cost models.

\section{Related Research and Current Practice}

Activity-based costing, theory of constraints, feature based costing, parametric costing and analogy are typical cost estimating and control techniques designed to provide more relevant information for evaluating the economic consequences of resource allocation decisions ${ }^{[1-5]}$. Almost all literature on estimating future costs or technology ${ }^{[6-8]}$ has been applied to large civil engineering projects or low volume aerospace projects, since these industries often rely on previously-developed estimates to win new contracts. The Jet Propulsion Laboratory in the United States has developed a parametric costing model for future space projects that is based on very little historical data ${ }^{[6]}$. It was argued that using historical data and relationships failed to produce accurate estimates on which to base budgets ${ }^{[7]}$. The research presented in this paper suggests that unique cost drivers mean that each project needs to be estimated on its own merits. Several iterations of estimates also need to be conducted, each one in greater depth than the previous one. Cost control needs to use these estimates as the basis for decisions once the budget has been set. Moreover, management support during cost control allows accurate budgets to be achieved. However, a major problem involves the level of resources required to compile each stage of estimates during the conceptual phases and the following reconciliation between them.

In order to capture current practice within the automotive sector, a series of semi-structured interviews and telephone interviews were organised with cost estimators with three different companies, one of them is the industry leader in cost estimating practices. It is observed, in the automotive sector different processes and procedures have been developed to help an activity achieve its commercial goal. For example, the Product Development System in one of the participating automotive companies determines how much a product can be sold for and then works back into system chunks and then into component level - although it fails to provide a costing function. The company uses activity based techniques for estimating costs 
when the target and supplier quotes are disconnected. All information is stored in a database and so every cost driver can be traced to its original figure, which is based on real world data. Cost drivers can be defined as the portions of a system, end item, or service that have a large or major effect on the total work activity or output ${ }^{[8,9,10]}$. But the current practice does not support cost estimation of New Technology intensive automotive products in a structured manner. Currently it is practiced in an ad hoc fashion. The next stage was to look at nonautomotive companies to understand their current practice.

Data for this part of the research was obtained from responses to a semi-structured questionnaire sent to twelve companies based in different industry sectors, including space, aerospace, oil, electronics and motor sports. The responses indicated that the application of new technology, whether new to the industry or to the company, was too insignificant to develop specialised costing routines. However, certain industries, such as space, regularly utilise new technology, and so have dedicated resources to costing future products, typically using the parametric approach ${ }^{[11]}$. A consultancy company also developed cost estimates for new or future technology; rather than focusing on a specific costing procedure, the company relied on the information available at the time of the study to determine the cost estimating routine. It is also important to consider that new technology solutions does not always contain all new ideas. For example, although Formula One motor racing cars are on the cutting edge of car dynamics, less than $15 \%$ of a development budget is assigned to new technologies

\section{Classification of New Technology}

Automotive companies have well-established procedures that dictate the methods of developing advanced technology and detail the milestones to be achieved. The most important of these for this research are referred to as 'concept readiness' and 'implementation readiness'. These analyse the concept, indicate that the technology fundamentally works, and verify that it can be manufactured, whilst meeting targeted deliverables with confidence levels estimated and risks defined. This research will target the post implementation stage of the concept design. The study focused on existing practice and documentation available within the automotive sector. It is observed that new technologies in general can be divided into 
three major categories: New to Mankind, New to Industry and New to an Organisation (Figure 1). The automotive industry often follow technology development [9], therefore very unlikely to adopt 'New to Mankind' type of technology. New technologies from other industries are often considered as mature enough and less 'risky' for automotive sector. It is also observed that within a part/system of a car existing and new technologies are often mixed. Therefore, while developing a methodology for cost estimating new technology intensive products, the product could be analysed for:

\begin{tabular}{|c|c|c|}
\hline Naw to Mankind & New to Industry & $\begin{array}{l}\text { New to } \\
\text { organisation }\end{array}$ \\
\hline Nanotechnology & Fuel Cells & $\begin{array}{l}\text { Gasoline Direct } \\
\text { Injection }\end{array}$ \\
\hline $\begin{array}{l}\text { This technology was } \\
\text { defined in the } 1980 \text { 's } \\
\text { and encompasses many } \\
\text { ideas, but probably the } \\
\text { most famous is the } \\
\text { technology's idea to use } \\
\text { miniature robots to } \\
\text { repair the human body } \\
\text { from within. The } \\
\text { automotive industry is } \\
\text { not known to be as yet } \\
\text { research its possibilities }\end{array}$ & $\begin{array}{l}\text { This technology was } \\
\text { discovered in the late } \\
\text { nineteenth century and } \\
\text { used in space } \\
\text { technology in the } 1960 \text { s } \\
\text { but it is only now that the } \\
\text { automotive are } \\
\text { researching the } \\
\text { technology }\end{array}$ & $\begin{array}{c}\text { This technology has } \\
\text { been developed by other } \\
\text { automotive } \\
\text { manufacturers and used } \\
\text { on high volume vehicles } \\
\text { for some time but it only } \\
\text { now that FMC is } \\
\text { adapting the idea for its } \\
\text { own high volume } \\
\text { vehicles }\end{array}$ \\
\hline
\end{tabular}

Figure 1: Types of new technologies

New

New content type for the company

New like

New with similar attributes to a specified design

Modified

Redesigned from an existing stated design

Carry over

Is exactly the same as an existing stated design

Once the concept is broken down into new technology and current or carry over technology, the respective systems can be entered into the correct cost model. The next section presents the methodology for 'New Technology Cost Model' development and follow a case study approach.

\section{Cost Model Development Methodology}

A case study based approach is followed to analyse the cost model development in detail. The cost model considers new products using either current technology and and/or new 
technology, and so needs to distinguish between the two areas. Figure 2 shows the flow and links between the different core areas of the model and the two distinct sub models for new or current technology. The model must accept the required data from the user and automatically generate a results sheet without further data manipulation. Both current and new technology cost estimating methods are required because the key deliverable for this research is to develop a process to cost new technology intensive products, inferring that there is some carry over of current technology. The case study is based on the Powertrain System.

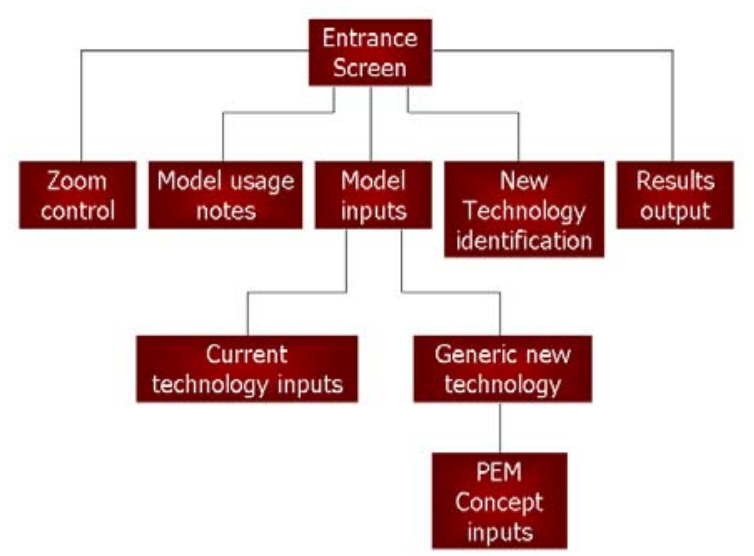

Figure 2: Model user interfaces flow

The process must be able to cost the current and new technology in a generic fashion and be applicable to more than one product type within the powertrain. Figure 3 shows how the model processes will flow; the concept for the new and carry over technology models is also shown. The process starts with the cost estimator receiving a request to examine a concept; the first task for the estimator is to segregate the new technology from the carry over technology. 


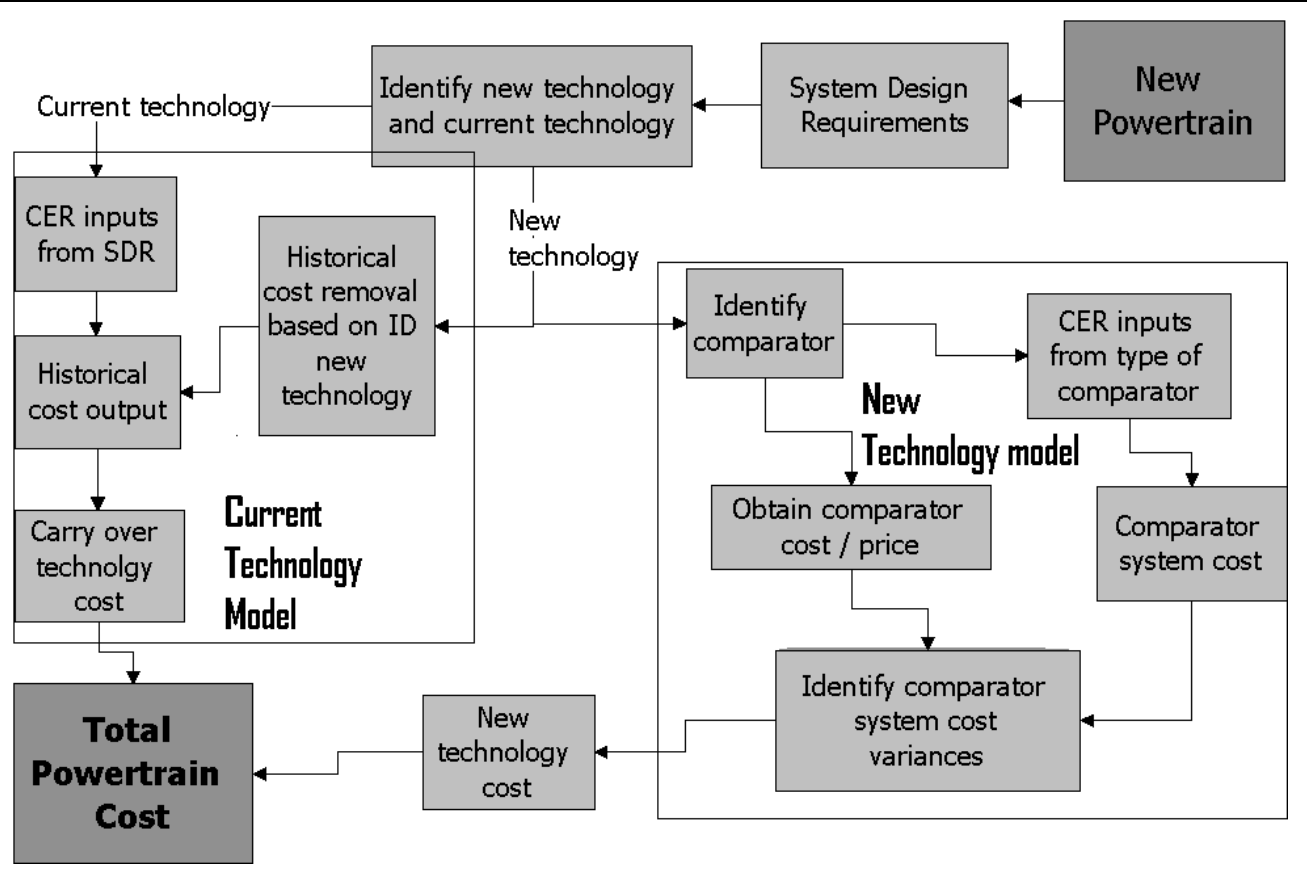

Figure 3: A conceptual process flow for the New Technology Cost Model.

The methodology includes use of historical data where relevant and expert judgement ${ }^{[12]}$ to perform the comparative study when necessary. The first task is to separate the carryover/current technology requirement from new technology requirement. This is a knowledge intensive task and requires domain expert participation. The cost of current technology intensive parts are then estimated based on cost estimating relationships (CERs) developed from historical data. Depending on the nature of the data stored previously, there may be a need to remove any double counting of cost due to the introduction of the new technologies. The new technology part is more complex. It depends on identifying a 'comparator' for the technology from other parts of the company or from non-automotive sectors. If a CER exists, that can be used with appropriate adjustments to reflect the differences with automotive sector. Otherwise, the cost has to estimated from an indication of cost of the 'comparator' through expert judgement. The methodology developed through this case study is then validated with two further case studies in section 9 .

\section{Current technology cost models}

Developing the total cost of the powertrain required a database of previous engine data. Since previous powertrains have been in the form of engines, the model is only able to estimate engines utilising current technology. The model will only cost high volume 
automotive powertrain products. Historical data was available from previous engines for the carry over technology model, although all possible cost drivers needed to be identified and tested for their relationship to cost to ensure that the correct data was collected. The potential cost drivers available in the concept stages of the design process included percentage of new technology, weight, size, fuel type, vehicle platform, size restrictions, efficiency of the system, product innovation, complexity, packaging and power output. Once the relevant attributes were identified, engine data was entered into a database and cost relationships established.

Eighteen current engines were broken down by their unique system code with the corresponding cost attached. The total normalised cost for each engine formed the data to be entered into multiple regression analysis. Figures from the UK Office of National Statistics monthly Producer Price Index were used against the cost of each engine and multiplied by a factor to obtain the same reference time frame. Total costs were distorted by different exchange rate publications from local currencies in the data.

\begin{tabular}{|c|c|c|c|c|c|c|c|c|c|c|c|}
\hline & & & Comparison number & 1 & 2 & 3 & 4 & 5 & 6 & 7 & 8 \\
\hline & & & Engine name & & & & & & & & \\
\hline & & & Engine Size (Litres) & 1.6 & 1.6 & 2.0 & 2.0 & 2.7 & 1.4 & 1.6 & $1.6 \mathrm{DVCT}$ \\
\hline & & & Date & Mar-92 & Jan-00 & Jan 00 & Jan 00 & Jan-01 & May-03 & May-03 & Jan-05 \\
\hline 03 & 00 & 00 & ENGINE SYSTEM & 10.00 & 20.00 & 30.00 & 40.00 & 50.00 & 60.00 & 70.00 & 80.00 \\
\hline 03 & 00 & 01 & Eng Ass - Ford Prod - SI - In-Line & 10.00 & 20.00 & 30.00 & 40.00 & & 60.00 & 70.00 & 80.00 \\
\hline 03 & 00 & 02 & Eng Ass - Ford Prod - SI - V & & & & & & & & \\
\hline 03 & 00 & 03 & Eng Ass - Ford Prod - Cl - In-Line & & & & & & & & \\
\hline 03 & 00 & 04 & Eng Ass - Ford Prod - $\mathrm{Cl}-\mathrm{V}$ & & & & & 50.00 & & & \\
\hline 03 & 00 & 05 & Eng Ass - Vend Prod - SI - In-Line & & & & & & & & \\
\hline 03 & 00 & 06 & Eng Ass - Vend Prod - $\mathrm{SI}-\mathrm{V}$ & & & & & & & & \\
\hline 03 & 00 & 07 & Eng Ass - Vend Prod - Cl - In-Line & & & & & & & & \\
\hline 03 & 00 & 08 & Eng Ass - Vend Prod - $\mathrm{Cl}-\mathrm{V}$ & & & & & & & & \\
\hline 03 & 00 & 09 & Ford Prod - SI -Rotary & & & & & & & & \\
\hline 03 & 00 & 10 & Vend Prod - SI - Rotary & & & & & & & & \\
\hline 03 & 00 & 11 & Ford Prod - N/A - Electric & & & & & & & & \\
\hline 03 & 00 & 12 & Vendor Prod - N/A - Electric & & & & & & & & \\
\hline 03 & 01 & 00 & Basic Engine Structure Subsystem & 21.00 & 27.00 & 33.00 & 39.00 & 45.00 & 21.00 & 27.00 & 33.00 \\
\hline 03 & 01 & 01 & Cylinder Block & 1.00 & 2.00 & 3.00 & 4.00 & 5.00 & 1.00 & 2.00 & 3.00 \\
\hline 03 & 01 & 02 & Cylinder Heads & 2.00 & 3.00 & 4.00 & 5.00 & 6.00 & 2.00 & 3.00 & 4.00 \\
\hline 03 & 01 & 03 & Intake Manifold & 3.00 & 4.00 & 5.00 & 6.00 & 7.00 & 3.00 & 4.00 & 5.00 \\
\hline 03 & 01 & 04 & Exhaust Manifold & 4.00 & 5.00 & 6.00 & 7.00 & 8.00 & 4.00 & 5.00 & 6.00 \\
\hline 03 & 01 & 05 & Flywheel Housing/Adaptor & 5.00 & 6.00 & 7.00 & 8.00 & 9.00 & 5.00 & 6.00 & 7.00 \\
\hline 03 & 01 & 06 & Engine Lifting Eyes & 6.00 & 7.00 & 8.00 & 9.00 & 10.00 & 6.00 & 7.00 & 8.00 \\
\hline 03 & 02 & 00 & Engine Lubrication Subsystem & 21.00 & 27.00 & 33.00 & 39.00 & 45.00 & 21.00 & 27.00 & 33.00 \\
\hline 03 & 02 & 01 & Oil Pump and Screen & 1.00 & 2.00 & 3.00 & 4.00 & 5.00 & 1.00 & 2.00 & 3.00 \\
\hline 03 & 02 & 02 & Oil Filter, Dip Stick and Filler & 2.00 & 3.00 & 4.00 & 5.00 & 6.00 & 2.00 & 3.00 & 4.00 \\
\hline 03 & 02 & 03 & Oil Pan and Reservoirs & 3.00 & 4.00 & 5.00 & 6.00 & 7.00 & 3.00 & 4.00 & 5.00 \\
\hline 03 & 02 & 04 & Engine Oil Cooler & 4.00 & 5.00 & 6.00 & 7.00 & 8.00 & 4.00 & 5.00 & 6.00 \\
\hline 03 & 02 & 05 & Oil Distribution & 5.00 & 6.00 & 7.00 & 8.00 & 9.00 & 5.00 & 6.00 & 7.00 \\
\hline 03 & 02 & 06 & Engine Lubricant & 6.00 & 7.00 & 8.00 & 9.00 & 10.00 & 6.00 & 7.00 & 8.00 \\
\hline 03 & 03 & 00 & Engine Cooling Subsystem & 1.00 & 2.00 & 3.00 & 4.00 & 5.00 & 6.00 & 7.00 & 8.00 \\
\hline
\end{tabular}

Figure 4: Engine Bills of materials by unique system code

The list of components and their prices were grouped under the respective code, which enabled all bills of material from each engine to be compared on a like for like basis. Figure 4 provides an example of the unique code listing with example engines and their price structure. 


\begin{tabular}{|c|c|c|c|}
\hline Description & Units of measure & Engine 1 & Engine 2 \\
\hline Cylinders / configuration & $\mathrm{I}=$ inline, $\mathrm{V}=\mathrm{vee}$ & 14 & 14 \\
\hline Cost (normalised) & USD & 700.00 & 500.00 \\
\hline Weight & $\mathrm{Kg}$ & 90 & 120 \\
\hline Size & $\mathrm{l} \times \mathrm{w} \times \mathrm{h}$ & $0.6 \times 0.45 \times 0.60$ & $0.65 \times 0.50 \times 0.65$ \\
\hline & $=c u \cdot M$ & 0.16 & 0.21 \\
\hline Volume & Annual volume & 500,000 & 500,000 \\
\hline Engine Size (Litres) & Litres & 1.6 & 2.0 \\
\hline Power & PS & 103 & 130 \\
\hline Date & Date & Mar-92 & Jan 00 \\
\hline Cylinders & Number & 4 & 4 \\
\hline Fuel number & $1=$ Petrol or $2=$ diesel & 1 & 1 \\
\hline Advanced technology content & Identified $\%$ of parts & $30 \%$ & $17 \%$ \\
\hline Engine family complexity & Engine variants & 3 & 2 \\
\hline Weight Ratio & $\mathrm{Kg} / \mathrm{cu} . \mathrm{M}$ & 562.5 & 571.4 \\
\hline Size Ratio & $\mathrm{PS} / \mathrm{cu} . \mathrm{M}$ & 643.8 & 619.0 \\
\hline Effeciency Ratio & PS / Itr & 64.4 & 65.0 \\
\hline Volume & Annual volume & 500,000 & 500,000 \\
\hline Vehicle type & $\begin{array}{l}\text { Sub } B=1 ; B=2 ; C=3 \\
C D=4 ; P A G=5 ; C V=6\end{array}$ & 3 & 4 \\
\hline Weight per cylinder & $\mathrm{Kg} / \mathrm{cyl}$ & 22.5 & 30 \\
\hline
\end{tabular}

Figure 5: Cost Driver Unit of Measure

Figure 5 highlights all possible drivers that were deemed quantifiable from the initial list. All factors are the measurements of the engine as it leaves the manufacturing plant. Units of measurement were placed against each element and a regression (least square best fit) report was produced from this data. The analysis highlighted the cost drivers listed in Figure 6 as the independent drivers of the engines studied. Please note the high value of the Rsquared, which shows the good quality of the data captured.

\begin{tabular}{|c|c|c|c|c|c|}
\hline $\begin{array}{l}\text { Independent } \\
\text { Variable }\end{array}$ & $\begin{array}{l}\text { Regression } \\
\text { Coefficient }\end{array}$ & $\begin{array}{l}\text { Standard } \\
\text { Error }\end{array}$ & $\begin{array}{c}\text { T-Value } \\
(H o: B=0)\end{array}$ & $\begin{array}{l}\text { Prob } \\
\text { Level }\end{array}$ & $\begin{array}{l}\text { Power } \\
-5 \%\end{array}$ \\
\hline Intercept & -11.97880 & $1,144.20100$ & -0.01050 & 0.99188 & 0.05001 \\
\hline Type of fuel & 526.18990 & 353.61640 & 1.48800 & 0.17092 & 0.26548 \\
\hline Advanced technology content & $1,863.89200$ & $1,220.91800$ & 1.52660 & 0.16120 & 0.27680 \\
\hline Engine family derivatives & 48.91518 & 37.70735 & 1.29720 & 0.22682 & 0.21332 \\
\hline Size relationship & 1.35989 & 2.25932 & 0.60190 & 0.56209 & 0.08406 \\
\hline Effeciency & -27.10024 & 27.38565 & -0.98960 & 0.34824 & 0.14391 \\
\hline Swept volume & -0.00086 & 0.00000 & 0.00000 & 1.00000 & 0.05000 \\
\hline Power & 12.83890 & 5.89954 & 2.17630 & 0.05753 & 0.49324 \\
\hline Installation vehicle type & -111.67330 & 91.53115 & -1.22010 & 0.25345 & 0.19414 \\
\hline R-Squared & 0.9750 & & & & \\
\hline
\end{tabular}

Figure 6: Multiple Regression Results

The cost drivers are described in more detail with sample data types below:

- Type of fuel powering the engine petrol

- Amount of advanced technology within the engine $20 \%$

- How many engine derivatives within the family 4

- Restriction to the size of the engine $P S / m^{3}$

- A calculated simple efficiency PS / Ltr

- Annual manufacturing volume of the engine plant 350,000

- Power output at source PS

- Type of vehicle the engine is to be installed in Platform

The 'Amount of advanced technology' is listed as a percentage using expert judgement, which the model calculates from the new technology unique system identification code. The 
calculation starts from the list of identified new technologies to be estimated; the model compares what has had cost associated historically to a particular system and is therefore included in the database associated with the regression analysis. If the identified technology has an attributed cost, then the identification will go towards the total percentage of new technology.

\section{New Technology Cost Models}

Once the new technologies have been classified, they need to be identified against the unique system descriptions. Figure 7 is an example of the system identification process with new technologies indicated. This classification means that new technologies can be costed within the new technology cost estimating relationships (CERs). The identification also feeds one of the CER drivers for the current technology. Any costs present in both the current and new technology models will be identified so that they can be removed from the current model.

\begin{tabular}{|c|c|c|c|c|}
\hline \multicolumn{3}{|c|}{ Code } & \multirow[t]{2}{*}{ Description } & \multirow{2}{*}{ New tech } \\
\hline 1 & 2 & 3 & & \\
\hline 03 & 00 & 00 & ENGINE SYSTEM & \\
\hline 03 & 01 & 00 & Basic Engine Structure Subsystem & \\
\hline 03 & 01 & 01 & Cylinder Block & $\mathbf{Y}$ \\
\hline 03 & 01 & 02 & Cylinder Heads & \\
\hline 03 & 01 & 03 & Intake Manifold & \\
\hline 03 & 01 & 04 & Exhaust Manifold & \\
\hline 03 & 01 & 05 & Flywheel Housing/Adaptor & \\
\hline 03 & 01 & 06 & Engine Lifting Eyes & \\
\hline 03 & 02 & 00 & Engine Lubrication Subsystem & \\
\hline 03 & 02 & 01 & Oil Pump and Screen & $\mathbf{Y}$ \\
\hline 03 & 02 & 02 & Oil Filter, Dip Stick and Filler & \\
\hline 03 & 02 & 03 & Oil Pan and Reservoirs & \\
\hline 03 & 02 & 04 & Engine Oil Cooler & $\overline{\mathbf{Y}}$ \\
\hline 03 & 02 & 05 & Oil Distribution & \\
\hline 03 & 02 & 06 & Engine Lubricant & \\
\hline 03 & 03 & 00 & Engine Cooling Subsystem & \\
\hline
\end{tabular}

Figure 7: New technology identification interface

The new technology cost model must be able to accommodate all new technologies. However, since each technology has a different set of cost drivers, a different model would be required for each one. To facilitate this, and to allow for future developments, the new technologies suite has been divided into a main general information screen and a specific cost model for the technologies. If the cost model fails to reflect the technology in question, there is a generic model that accommodates all other technologies. 
Once the new technology content for the powertrain has been identified, it can be processed through the new technology cost model. The first stage of this process is to group the identified technologies into a maximum of five overall systems. For technologies that have been identified and a relationship mapped, there will be a specific user interface, and these models are termed 'identified new technology relationships'. The estimate process follows the right hand side of Figure 8 if a cost model is available for a particular technology. Once the appropriate new technology interface is located, the user enters the data required from a comparator that has been identified as similar to the product under investigation. The generic modelling process is used if the new technology being investigated does not have a specific CER within an interface. This is called the non-identified new technology model and the process follows the left-hand side path of Figure 8, starting with the user entering a number that represents either the cost or the price of a comparator system.

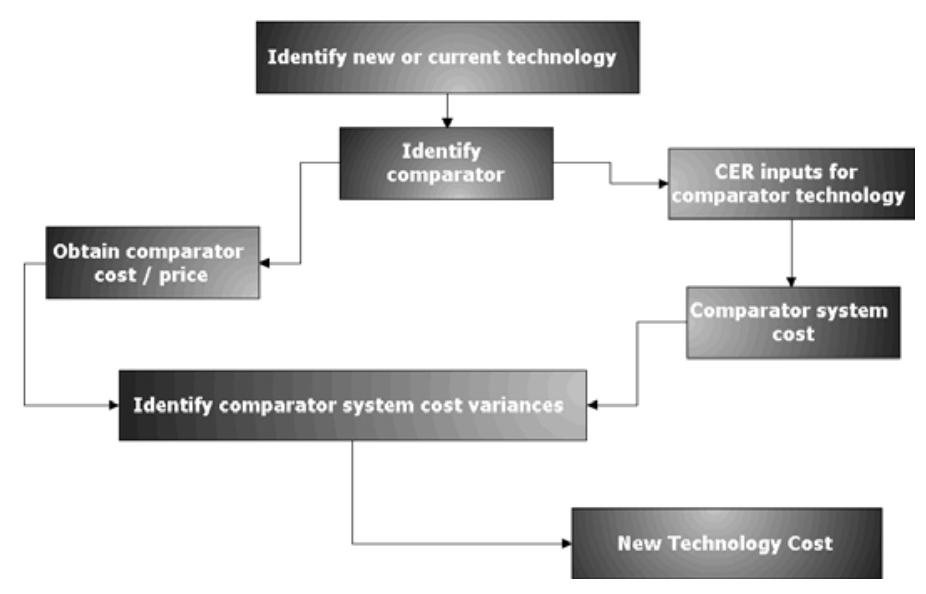

Figure 8: New technology model process routes

Differences exist between cost and price, which should be reflected in the data accompanying the estimate. If the comparator is estimated, the methodology behind estimating a comparator instead of the actual system is that the comparator is already available and manufacturing methods and materials can be identified, and a detailed estimate compiled. Together with the financial data of the system, the comparator would use the comparator system definition and the new system definition to produce the concept cost model. Fuel Cell ${ }^{[13]}$ is identified as the comparator system for the case study. The nature of the cost model meant that some details describing the fuel cell system were required as inputs. However, since there are as yet no available high volume production costs for fuel cells, an existing detailed costing exercise focusing on fuel cells was utilised. The study was performed by Directed Technologies Inc. for 
Ford under contract to the United States Department of Energy Office of Transportation Technologies (contract no. DE-AC02-94CE50389) ${ }^{[13]}$. A cost model was developed with the equation published that applies to a system production of 300,000 units per annum.

$$
C_{H V}=1073+P_{N}\left(3.27+\frac{5.34+27 x L_{P}}{P_{D}}\right)
$$

Where; $\mathrm{C}_{\mathrm{HV}} \quad=$ high volume cost of fuel cell system (USD)

$\mathrm{P}_{\mathrm{N}} \quad=$ net fuel cell peak power output $(\mathrm{kW})$

$\mathrm{L}_{\mathrm{P}} \quad=$ total cell platinum catalyst loading $\left(\mathrm{mg} / \mathrm{cm}^{2}\right)$

$\mathrm{P}_{\mathrm{D}} \quad=$ cell peak power density $\left(\mathrm{W} / \mathrm{cm}^{2}\right)$

These drivers were incorporated into an interface similar to the combustion engine model and the other new technology data entry screens. Similar to the generic new technology interface, the fuel cell interface utilises a comparator and cost walk system.

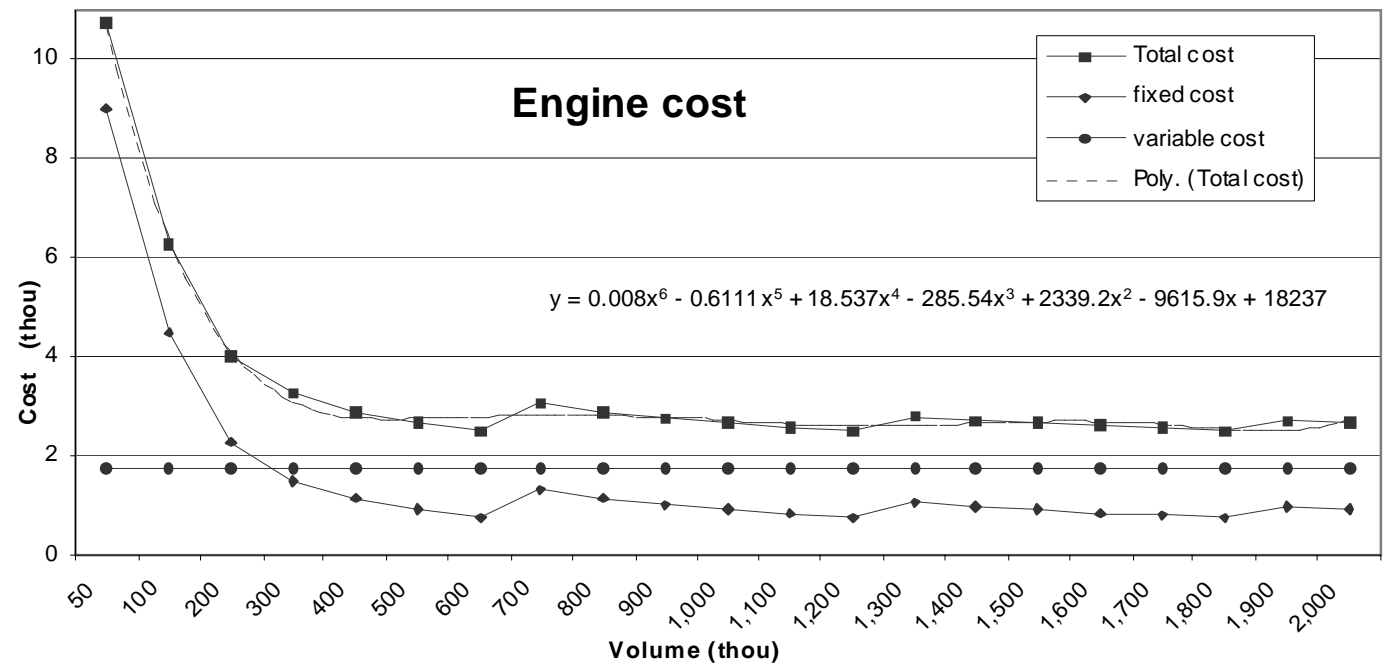

Figure 9: Cost versus volume relationship

As with any cost estimate, a production volume was assumed, enabling manufacturing methods to be attributed to the design. Since this cost model must be able to accommodate more than one volume scenario, Ford manufacturing plants were analysed to determine the effect of volume on the total cost; Figure 9 shows the results. Confidentiality prevents the actual costs represented on the $y$-axis from being disclosed, but the relationships depicted are correct and show that fixed costs are static no matter what volume is produced. Variable costs had the largest volume influence on the total engine cost; they decrease significantly with volume, until the manufacturing line is at maximum output. Volume cost temporarily 
increases because the costs of a new line have to be recouped. The research by Directed Technologies assumed that 300,000 products per annum would be produced. The research presented in this paper assumed 300,000 to be half the maximum volume of the manufacturing line, since the new technology is in the early stages of mass production and so not at full production volumes. From this, the relationship in Figure 9 is applied to the results from the fuel cell estimating equation to adjust the comparator cost depending on the volume.

Once the cost of the comparator product has been established, the estimate has to be at variance to the new concept under investigation using the comparator to concept technology process. Stating a small number of high-level characteristics and asking the user to scale the cost movements within a predefined scope calculate this migration. The first step of this process is to identify the areas of largest influence within the systems, which was achieved through responses provided by five estimators to a semi-structured questionnaire. The concept of systems was emphasised, since they contain multiple primary manufacturing processes rather than commodities, which are usually grouped by the primary manufacturing process, such as plastic injection moulding. Attempting to identify the key drivers for systems that were not specifically one manufacturing process gave a wide range of results (Figure 10).

\begin{tabular}{lrlr}
\multicolumn{1}{c}{ Cost element } & \%* & \multicolumn{1}{c}{ Cost element } & $\%{ }^{*}$ \\
\hline Complexity & 4.0 & Patent technology & 1.8 \\
Component design & 1.4 & Plant location regionally & 0.6 \\
Count of materials involved & 2.2 & Plant untilisation & 3.8 \\
Customer application & 2.4 & Sales volume & 4.4 \\
Design tolerances & 3.4 & Single or multiple sourced & 0.4 \\
Labour intensity & 2.6 & Size & 2.8 \\
Manufacturing process & 22.6 & System design & 4.8 \\
Material & 28.0 & System innovation & 5.0 \\
Number of parts in the design & 3.6 & System integration & 1.0 \\
Package requirements & 2.2 & Weight & 3.0 \\
*\% is average across all results & & &
\end{tabular}

Figure 10: Product elements with cost influence

The top six cost influencing elements were materials, innovation, manufacturing process, manufacturing volume, component design, and complexity. Two of these elements had a relatively small influence, and so they were re-presented to the estimators for revision, resulting in them being combined with others as shown in Figure 11. 


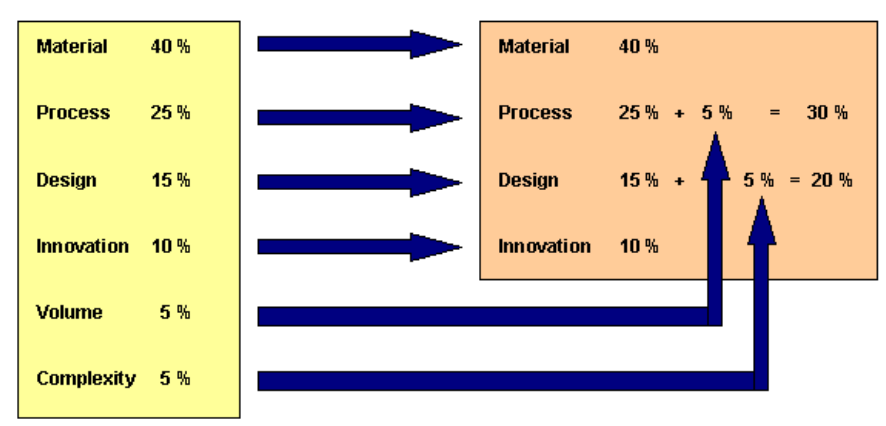

Figure 11: System cost drivers

Figure 11 also shows the ranking and weighting given to the four remaining drivers. Following identification of the key elements for systems cost drivers, the comparator product could be financially walked to the new system under investigation. A basic model was built that enabled the user to compare the estimated/priced system with the one under analysis using the four areas of movement identified in Figure 11. The model variance used a range of numbers from negative three to positive three centring on zero to dictate movement in a particular area. A model and process was then built utilising these drivers as described in the numbered points below and in Figure 12 .

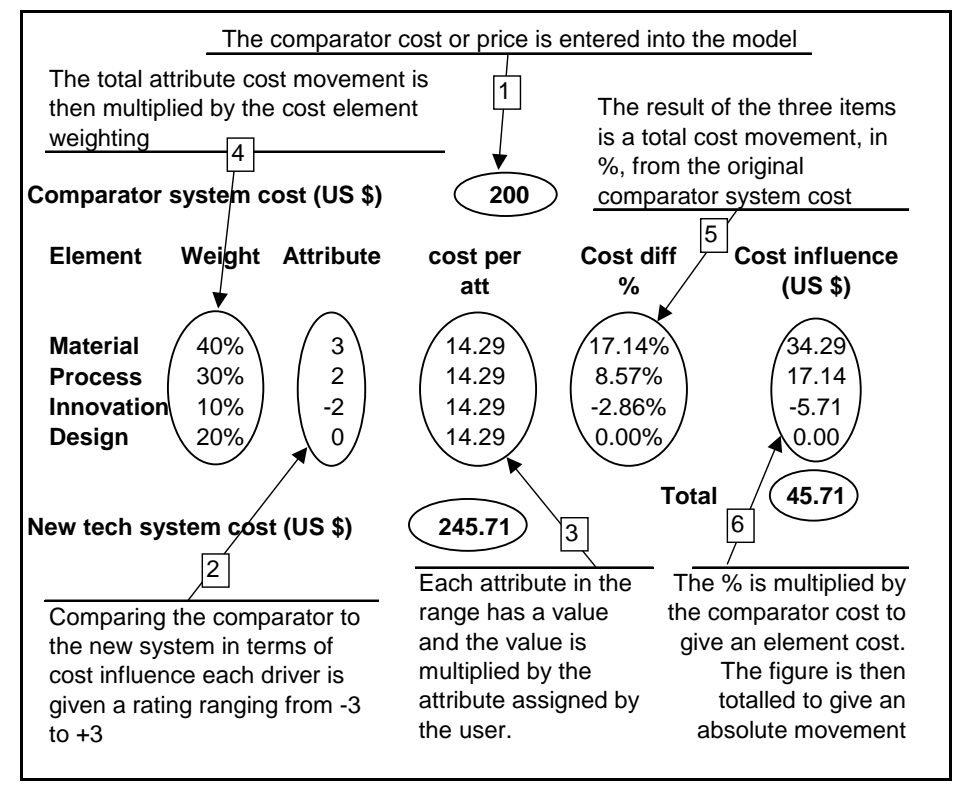

Figure 12: Comparator cost walk

1. The program enters the identified comparator system price or cost into the model.

2. The comparator is analysed against the new system under the key elements stated previously. A positive figure indicates the new product is more expensive whereas 
cheaper products have a negative figure. The magnitude of the figure indicates the size of the cost difference.

3. Each movement increment is given a value. The model has a maximum of $50 \%$ movement from the zero baselines to the maximum movement of plus or minus three, thus assigning each increment 14.29 percentage points.

4. The total movement stated within step [2] is multiplied by the increment value identified in step [3]. The result is a total movement within the system cost for each element.

5. To give a figure that represents the percentage movement as a total of the elements, the figure resulting from [4] is multiplied by the elemental weighting given in each element and displayed as a percentage.

6. The percentage is calculated as a numerical figure of the comparator cost stated in step [1]. These are then totalled and added to the comparator cost to give a new system cost.

Figure 13 is an example of the results the user sees for each technology under investigation. Element costs are shown on the left, totals on the right. The first total is the original comparator, then the cost walk to the new system and finally the total new cost for the new system under investigation.

$\begin{array}{lrlr}\text { New technology cost effect } & \text { System costs } & \text { USD } \\ \text { Material } & \mathbf{- 2 4 9 . 2 7} & \text { Comparator system cost } & \mathbf{2 1 8 4} \\ \text { Process } & \mathbf{0 . 0 0} & \text { New technology } & -\mathbf{2 1 8} \\ \text { Innovation } & -\mathbf{3 1 . 1 6} & & \\ \text { Design } & \mathbf{6 2 . 3 2} & \text { Total system cost } & \mathbf{1 9 6 5}\end{array}$

Figure 13: Comparator cost walk results layout

\section{Cost estimate adjustments model}

The estimates for each new technology and current technology content were collated into a single cost estimate applicable for a product launch timeframe. This collation and timeframe creates two issues that were addressed within the "Year of implementation economics adjustment" and "Current technology cost adjustment" models. The first issue is that the programme estimates all the areas of technologies within the product at current conditions, and so the product would have to be launched within the year of analysis to have any relevance to the estimate. This was unacceptable, since the model must be able to cost 
products that are due to be launched in five or ten years' time. One method to forecast future economics was to examine past trends in the form of the Producer Price Index.

The data begins in 1974, with a gradual increase in the index to the present day, with 1995 used as the zero base. However, there is a slight decline in the gradient over time and a projection from this basis could result in a misrepresentation of the data. Therefore, a second chart was produced utilising the data from 1995 onwards and projecting the trend forwards to 2005 using the least squares method; see Figure 14. If the need arises for data to project forward by ten years, then the use of the full dataset would be recommended with the overall decline in gradient taken into consideration. From the trend line formula, a routine was developed that takes both the current technology cost and the new technology cost and multiplies them by the factor identified in the formula.

The model in this state creates a 'double count' of some costs that must be eliminated. The current technology suite estimates an absolute cost for a complete engine, whilst the new technology models generate absolute costs for each new technology system. Therefore, the identified new technology systems must be removed from the current technology cost.

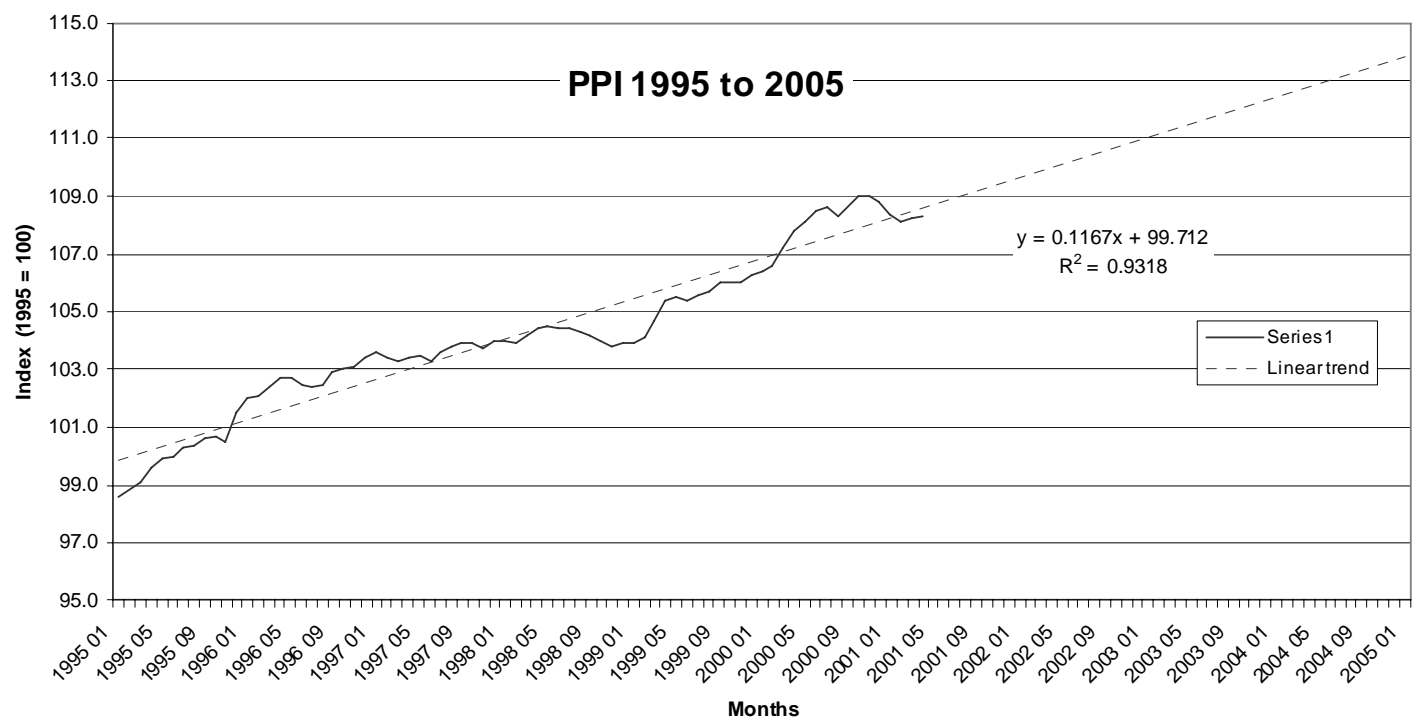

Figure 14: Producer Price Index for 1995 to present with trend projection 
The cost removal process starts from the list of identified new technologies to be estimated. From this list, the model compares what had cost associated historically to a particular system and therefore included in the database associated with regression analysis. If the technology had an attributed historical cost, the identification goes towards the current technology cost removal. If the identified technology was a new area and did not have a historical cost associated with it, it does not go towards cost removal. The cost removal process is based on the same input as the new technology identification. From the database of engines used for the regression analysis, each system within each engine was attributed a percentage based on system cost versus engine cost. These percentages were then averaged to provide a generic engine cost percentage breakdown; Figure 15 provides an example of the data. The historical percentage attributable to each new technology is then identified and added together to give a total percentage to be removed from the calculated current technology engine cost.

\begin{tabular}{|c|c|c|c|c|c|c|c|c|}
\hline & & & Comparison number & 1 & & 2 & & Average \\
\hline 03 & 00 & 00 & ENGINE SYSTEM & 1000 & $\%$ & 700 & $\%$ & $\%$ \\
\hline 03 & 01 & 00 & Basic Engine Structure Subsystem & 307.00 & $30.70 \%$ & 268.00 & $38.29 \%$ & $32.46 \%$ \\
\hline 03 & 01 & 01 & Cylinder Block & 150.00 & $15.00 \%$ & 150.00 & $21.43 \%$ & $12.31 \%$ \\
\hline 03 & 01 & 02 & Cylinder Heads & 100.00 & $10.00 \%$ & 85.00 & $12.14 \%$ & $12.31 \%$ \\
\hline 03 & 01 & 03 & Intake Manifold & 40.00 & $4.00 \%$ & 30.00 & $4.29 \%$ & $4.62 \%$ \\
\hline 03 & 01 & 04 & Exhaust Manifold & 15.00 & $1.50 \%$ & 2.00 & $0.29 \%$ & $3.08 \%$ \\
\hline 03 & 01 & 05 & Flywheel Housing/Adaptor & 0.00 & $0.00 \%$ & 0.00 & $0.00 \%$ & $0.00 \%$ \\
\hline 03 & 01 & 06 & Engine Lifting Eyes & 2.00 & $0.20 \%$ & 1.00 & $0.14 \%$ & $0.15 \%$ \\
\hline 03 & 02 & 00 & Engine Lubrication Subsystem & 49.00 & $4.90 \%$ & 38.00 & $5.43 \%$ & $5.38 \%$ \\
\hline 03 & 02 & 01 & Oil Pump and Screen & 20.00 & $2.00 \%$ & 15.00 & $2.14 \%$ & $3.08 \%$ \\
\hline 03 & 02 & 02 & Oil Filter, Dip Stick and Filler & 2.00 & $0.20 \%$ & 3.00 & $0.43 \%$ & $0.15 \%$ \\
\hline 03 & 02 & 03 & Oil Pan and Reservoirs & 25.00 & $2.50 \%$ & 15.00 & $2.14 \%$ & $0.62 \%$ \\
\hline 03 & 02 & 04 & Engine Oil Cooler & 0.00 & $0.00 \%$ & 0.00 & $0.00 \%$ & $0.77 \%$ \\
\hline 03 & 02 & 05 & Oil Distribution & 0.00 & $0.00 \%$ & 0.00 & $0.00 \%$ & $0.00 \%$ \\
\hline 03 & 02 & 06 & Engine Lubricant & 2.00 & $0.20 \%$ & 5.00 & $0.71 \%$ & $0.77 \%$ \\
\hline
\end{tabular}

Figure 15: A generic breakdown of engine costs

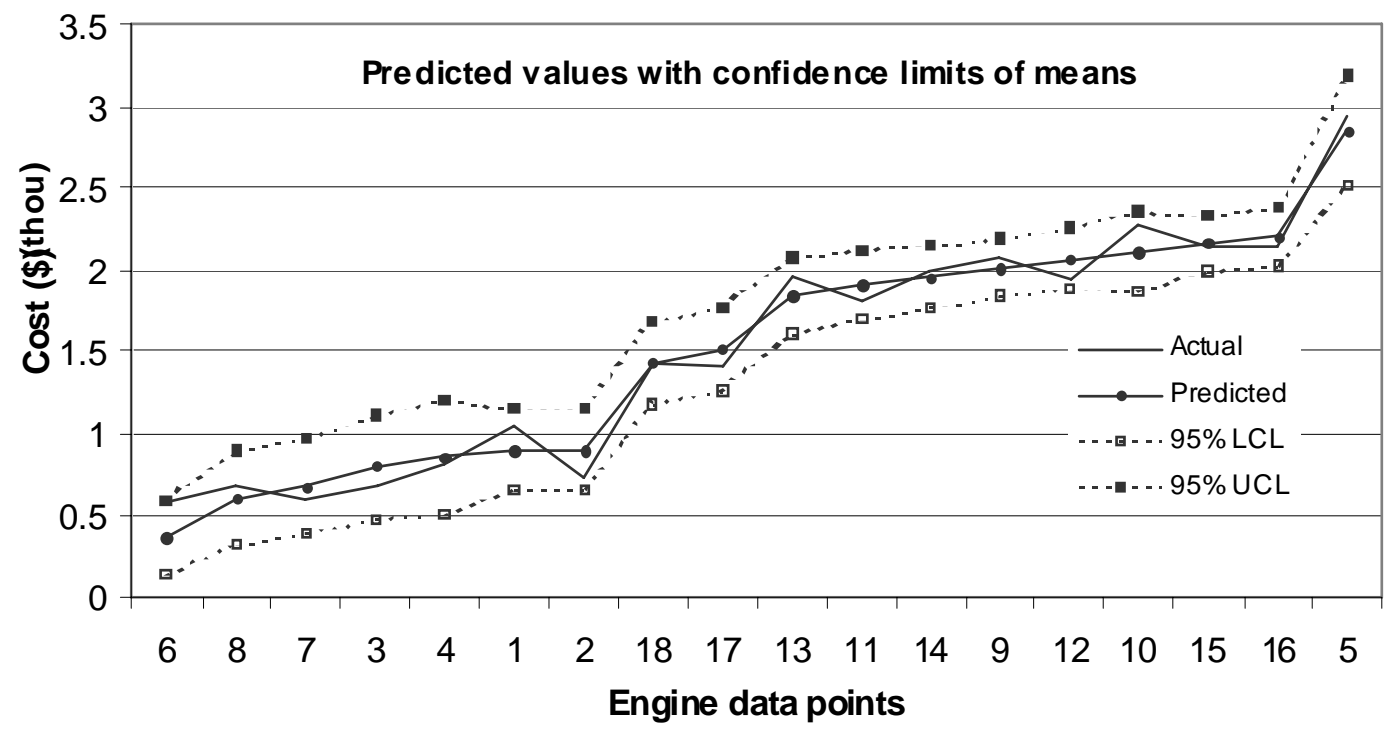


Figure 16: Predicted costs versus actual costs

Once all the costs have been collated, and any adjustments made depending on the user's request, the model will report a summary of the estimate as described in the following section.

\section{Results output}

The model is implemented in Excel. The key deliverable to this part of the programme was that all results produced were to be automatically generated onto a result page. Therefore, a user interface was developed that gave the estimator the current situation of the estimate without having to manually input any additional data. For ease of use and easy reference, the results page was divided into four key areas: the general environment in which the estimate has been created, the powertrain details that are being estimated and the page detail changes depending on the type of powertrain being investigated, the new technology breakdown, and the total cost estimate for the powertrain.

\section{Cost Model Validation}

Two case studies were used to evaluate the model. The first study was of a combustion engine that had recently been introduced into production within the company but had not been included in the original data set, while the second study tested the model when the base powertrain was not a combustion engine. The model and processes were validated by estimating the cost of these products and comparing them with the actual data from the true cost. Prior to the case studies, the engine-input data used to capture the drivers were re-input into the model to determine the predicted cost versus the actual cost. Figure 16 shows the results. A spark ignition engine of four cylinders inline configuration was selected for the first study. Design of the product was conducted on a worldwide basis with the assumption that it would be the new multipurpose power unit for new vehicles and therefore is available in many configurations for different applications. As suggested in the model development, this data was obtained from the system design assumption list.

The complete list was analysed to determine the content of new technology. The identified systems and component assemblies totalled greater than the amount of new technology 
areas able to be entered. Therefore, either the systems were grouped together, if appropriate, or omitted if deemed insignificant. The five systems that needed to be run through the new technologies costing suite were Engine Structure, Engine Lubrication, Emissions Control, Engine Sealing, and Power Conversion.

The new technology systems were then identified as to their specific new developments, with similar components present on different engines being used as the base comparators. In order to compare the estimated cost to the actual powertrain in production, the confidential nature of the cost of the engine within the company means the following statements become more ambiguous. All the data and relationships on the predicted value graph are true. Although a different engine is present on the graph, similar powertrains are present. Interpolating between the nearest units to the case study puts the cost within the confidence limits stated. Figure 17 presents the results of the model output for this case study; expert cost estimators within Ford found the results to be realistic.

In the second case study, a new technology was used to test the model with no carry over technology, this being fuel cells. Most major automobile manufacturers plan to launch a fuel cell powered vehicle by $2003 / 2004$, with reasonable volumes achieved by 2007 . Therefore, 2007 will be used as the year of implementation input in the model. Published data states that $60 \mathrm{~kW}$ to $85 \mathrm{~kW}$ is more realistic in the shorter term, keeping costs as low as possible ${ }^{[14]}$. This report states that using a carbon polymer composite cell would help to achieve a cost goal of under $\$ 30$ per $\mathrm{kW}$. The data used as the basis for this statement is that volume is the main contributor to cost reductions for this technology; therefore, a reasonable total volume produced will be set at 450,000 units. The other inputs required for the model were:

- Net fuel cell power output

口 Total cell platinum catalyst loading

- Cell peak power density
$(\mathrm{kW})$

$\left(\mathrm{mg} / \mathrm{cm}^{2}\right)$

$\left(\mathrm{W} / \mathrm{cm}^{2}\right)$ 


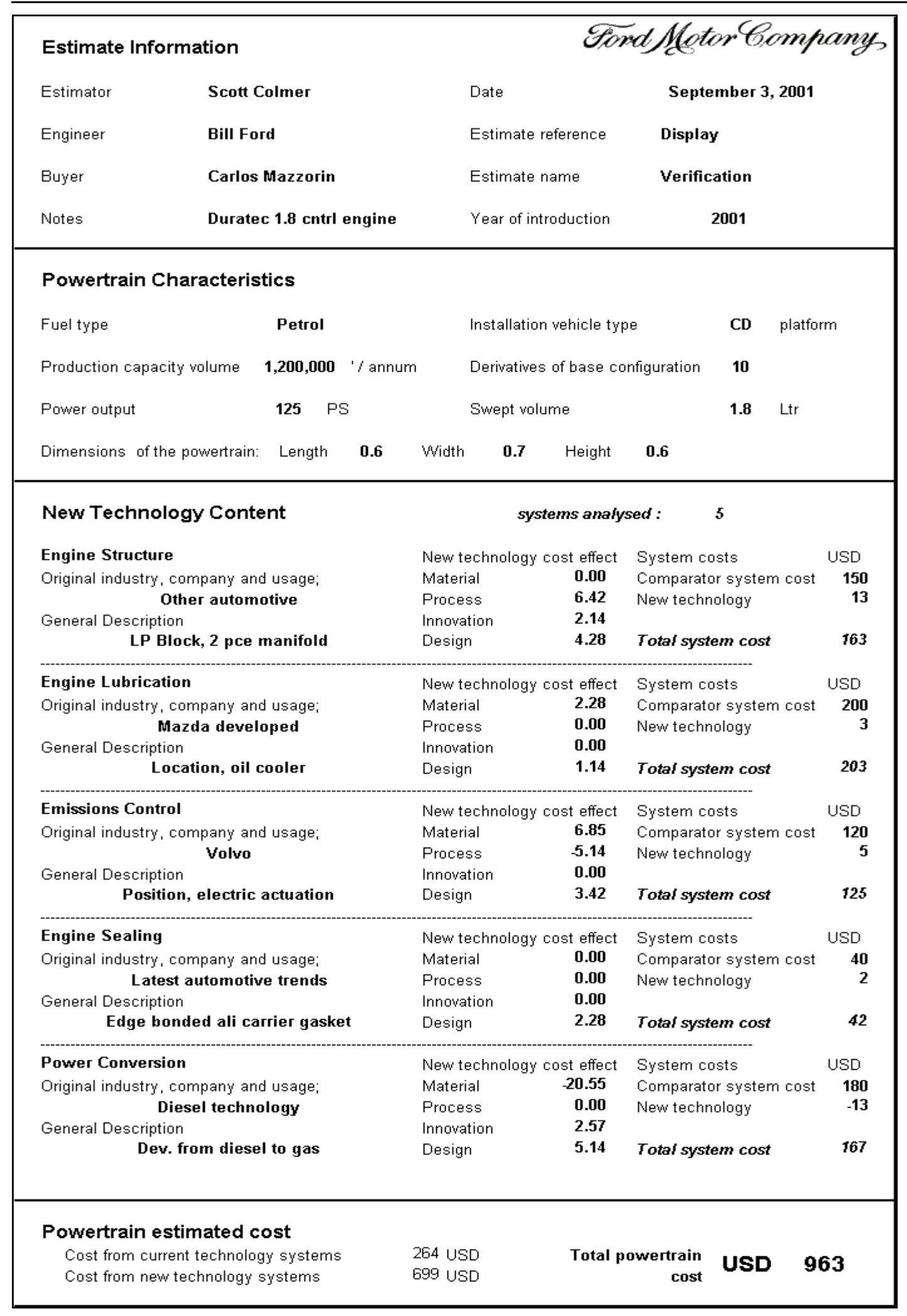

Figure 17: Combustion engine case study model result 


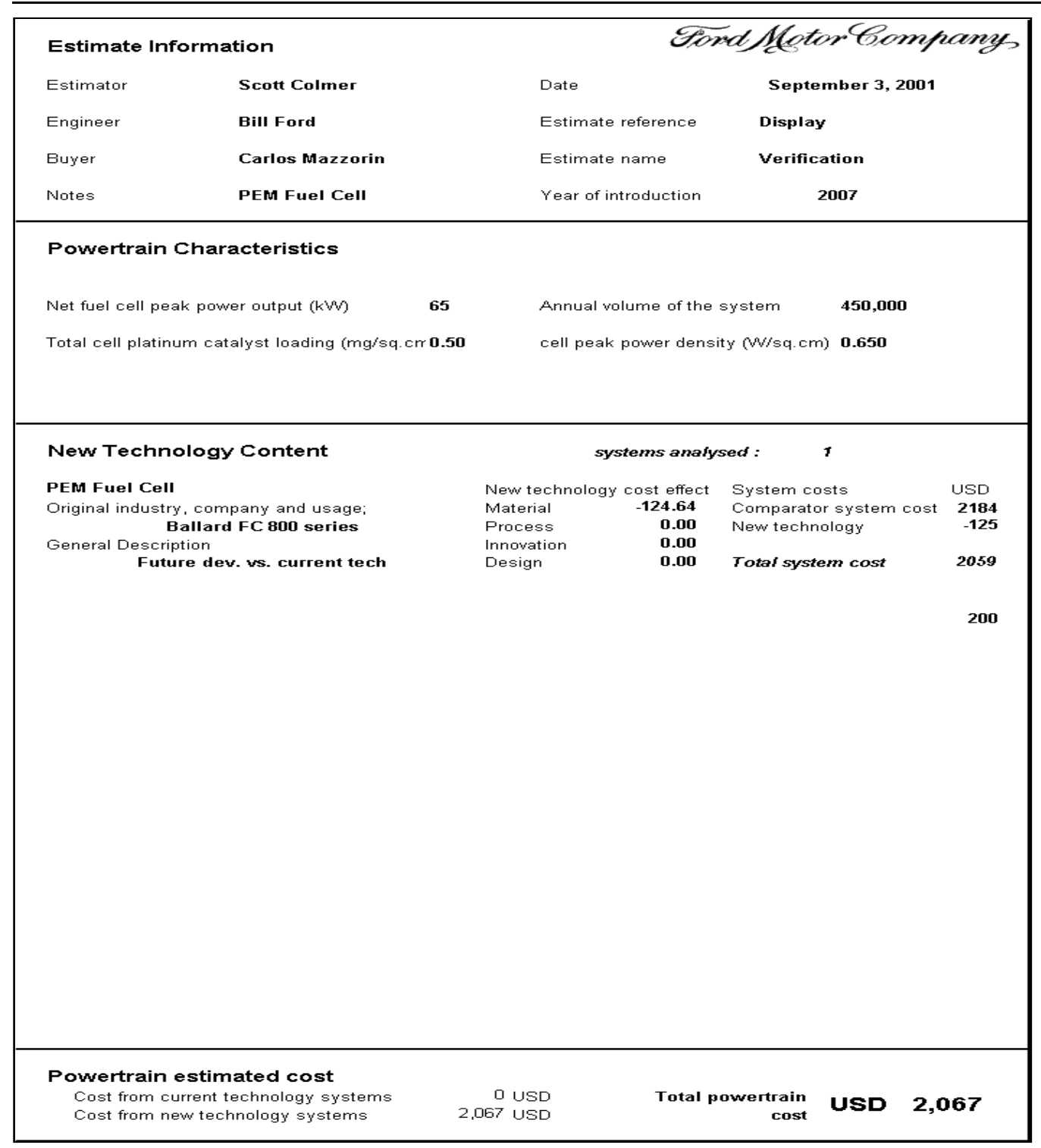

Figure 18: Proton Exchange Membrane fuel cell case study model results

If the results of this study are compared to the statements made in reference 15 , then the costs are slightly higher than expected at $\$ 31.8$ per $\mathrm{kW}$, but are in the correct region. Figure 18 presents the actual results, although they cannot be verified against any confidence limits or past data since the result and the CER are based on research that has yet to occur. The results were validated qualitatively by a cost estimating manager and three practicing cost estimators. They agreed the results are reasonable. 


\section{Discussion of the models}

Several areas of the cost model could be improved with further research or development. Environmental complexity means it is impossible to model all eventualities and scenarios, and so the most important environment factors needed to be identified. For current technology, multiple regression was used to model the environment. This technique has been thoroughly researched over time and so, if all assumptions of the technique have been met, the user can be confident of the result being within the upper and lower control limits. However, the generic new technology estimating section of the model is a more significant limitation of the approach. Research within this project identified a CER for proton exchange membrane fuel cells that was introduced into the model to enhance the subject area of new technology cost modelling. A different source for the comparator cost is needed if the new technology is different to proton exchange membrane fuel cells. The research methodology also made several assumptions for the future direction of the project. This included a stage in the development of a concept that a technology is ready to be implemented into a future production programme, which would also be ideal to initiate a cost estimate from this model. This would be ideal if resources allowed each new concept to be costed at the concept implementation stage. However, many different concepts reach this stage but not the final stages of development. The correlation between prototypes and final production systems was another area identified for potential inclusion in the model.

An element of risk is involved when using this model. The most significant risk is that the model gives a single point estimate, and so it is unlikely that the cost of the powertrain will match the estimate produced when the product is a concept. Confidence limits are established when the regression analysis formulates an R-squared value, and, in the case of this research, the confidence limit was targeted at 95\%. A second major risk within the model is the subjectivity of the new technology cost movement from the comparator technology. In order to enable consistency and repeatability between users and occurrences, the process has been developed with the removal of as much subjectivity as possible. However, unless a single answer can be input with the model calculating all further iterations, the model will always have subjectivity. Other inherent risks are the assumptions that have been made to 
build the model ${ }^{[9]}$. The model user must be aware of all of these assumptions and their affect on the estimate ${ }^{[12]}$. The literature survey focused on several areas of cost estimating, including the diverse ways that different organisations and industries have attempted to estimate new technology or projects that are not due to be completed for several years. One of the downfalls of the survey is that the companies were unwilling to disclose their methods. Another point revealed by the literature survey is that most cost estimating routines depend on the circumstances the estimate is required for and the information available at the time of estimate request. The logical step from this would be for the estimator to be furnished with a range of tools, all adapted and optimised for automotive, high volume production, and the knowledge to utilise these tools and the information available to the best advantage. Risk analysis of the estimates was not developed in the cost model. Several key factors have been addressed within the model, including CERs on powertrain system technology using either current combustion engine concepts or the as-yet-to-be introduced proton exchange membrane fuel cell. Several other relationships are published within this model, including volume relationships on the system, future economics, and system cost attributes.

The ability to scale up was a key concern when developing the model. Most work in this area would be the addition of CERs for other new technologies as and when required. Developing other areas of the vehicle would require considerable research that leads to the development of a separate model, since the other areas (body, chassis, and electrical engineering) are quite diverse. The smaller capacity combustion engine is an area within the model that would benefit from further research. As demonstrated in Figure 16, the cheaper end of the graph might have started to diverge away from the predicted values. It will not be known what represents the true world data until further engines are added to the database in this area. Additional benefit would be gained if the volume influence relationship was researched in greater depth. The model within this research was depicted from one manufacturing plant. The CER would be more robust if other plants were added. 


\section{Conclusions}

It can be concluded from the research that:

a. A structured methodology to perform cost estimating for products with high levels of new technology does not exist.

b. Three types of new technology can be used in cost estimating: new to organisation, new to industry, and new to mankind.

c. A methodology to separate the use of current technology versus new technology in a product has been developed.

d. A structured methodology has been developed for cost estimating new technology-intensive products.

e. The methodology has been implemented in an Excel spreadsheet and evaluated through two case studies.

f. The limitations of the models and the research methodology have been identified.

The inclusion of risk analysis and confidence in a reported estimate is one area where the model would benefit from further research. This tool would provide an added dimension to decision-makers within an automotive company, either to further develop technologies or focus on certain high cost elements. Including risk analysis would expand the model scenarios and allow the business decision to be based upon more robust fundamentals. The model currently produces an estimate that details a cost with a known confidence, but fails to not detail what would happen if elements of the estimate were changed. It is not possible to use this model to manage day-to-day costs incurred in a manufacturing facility, but it is ideal for developing strategies or estimates for products that are only in the concept stages of development. 


\section{References}

[1] Kee, R., Schmidt, C. (1998). A Comparative Analysis of Utilizing Activity Based Costing and the Theory of Constraints for Making Product Mix Decisions. International journal of production economics $\mathrm{V} 63,1-17$

[2] Pugh, P.G. (1992). Working Top Down: Cost Estimating Before Development Begins. PIME 206

[3] Shepperd, M.J., Scholfield, C. (1997) Estimating software project effort using analogies. In: IEEE Transactions on software engineering. V23-12

[4] Myrtveit, I., Stensrud, E. (1999). A controlled experiment to assess the benefits of estimating with analogy and regression models. In: IEEE Transactions on software engineering. V25-4

[5] Roy, R. (2003). In: Decision Engineering Report Series, Edited by: Roy, R. and Kerr, C. Cranfield University. ISBN 1-861940-96-3.

[6] Rosenberg, L. (1998). Parametric Cost Modelling of Unmanned Space Projects When the Rules Have Just Changed. In: $1^{\text {st }}$ Annual Joint ISPA/SCEA International Conference. USA

[7] Crawford, L.J., Coughlin, T.B., Ebert, W.L. (1996). Cost estimation and modelling for space missions at APL / JHU, In: Acta Astronautica 39, 255-264

[8] Bendall, D., Crossland, J., Hamel, J., Jones, P., Palacio, A., Taylor, J.P., (1999).Development of Airframe Engineering CER's for Military Aerostructures. In: Proceedings of the second world manufacturing congress, UK.

[9] Colmer, S (2002). Developing a Cost Estimating Methodology for New Technology Intensive Products. MSc by Research Thesis. Cranfield University (UK).

[10] Roy, R. Souchoroukov, P. and Kopponen, H. (2003). Information Requirements for Cost Estimating and the Automotive Industry. The 8th Annual ASME Design for Manufacturing Conference, Chicago, Illinois 2-6 September, Paper Reference: DETC2003/DFM-48153.

[11] Parametric Cost Estimating Initiative. (2000). Parametric Cost Estimating Handbook. Department of Defense I North American Space Agency. USA.

[12] Rush, C., Roy, R. (2001). Expert judgement in cost estimating: modelling the reasoning process, Concurrent Engineering: Research and Applications (CERA) Journal, 9(4). 271-284. 
[13] Lomax, F.D., James, B.D., Baum, G. N., Thomas, C.E. (1998) Detailed Manufacturing Cost Estimates for Polymer Electrolyte Membrane (PEM) Fuel Cells for Light Duty Vehicles. FMC and US DoE. Contract DE-AC02-94CE50389

[14] Lomax, F.D., James, B.D. (1997). PEM Fuel Cell Cost Minimization using "Design for Manufacture and Assembly" Techniques. In: 8th Annual US Hydrogen Meeting. Alexandria, USA

[15] Parametric Cost Estimating Initiative. (2000). Parametric Cost Estimating Handbook. Department of Defence / North American Space Agency. USA. 